Issue no. $27 / 2018$

\title{
STUDY REGARDING ROMANIAN STUDENTS' PERCEPTION AND BEHAVIOUR CONCERNING THE FINTECH AREA WITH A FOCUS ON CRYPTOCURRENCIES AND ONLINE PAYMENTS
}

\author{
Assoc. Prof. Dr. Florin Duma \\ Faculty of European Studies, Babeș-Bolyai University, Cluj Napoca, Romania \\ florin.duma@ubbcluj.ro \\ Raluca Gligor, M.Sc. \\ M.Sc. Student \\ Faculty of European Studies, Babeș-Bolyai University, Cluj Napoca, Romania \\ ralucagligor09@gmail.com
}

\section{DOI:10.24193/OJMNE.2018.27.04}

\begin{abstract}
Fintech, which is a shorthand expression for financial technology, is basically referring to all the technological innovations in the financial sector that started to develop exponentially, especially in the second decade of the 21 st century, in the era of the mobile internet revolution. The Generation Z, also called Gen Tech, who was growing up using the internet and especially the mobile internet on a daily basis, will probably be the larger adopter and beneficiary of these innovative financial technologies. The current generation of students, born about twenty years ago, is part of this cohort and this is why we decided to initiate a study regarding their perception and behavior concerning the fintech area with the help of a questionnaire applied on some of the students of the Faculty of European Studies from Babes-Bolyai University. Because the fintech is covering financial innovations from a very broad area (including cryptocurrency, online payments, financial transfers, openbanking, investments, regtech, insurtech, etc.) we decided to focus in this preliminary study, only on the blockchain technology and cryptocurrencies and in relation to these, on the online payments.
\end{abstract}

Keywords: Fintech, blockchain, cryptocurrencies, Bitcoin, online payments, cyber security. 
Issue no. $27 / 2018$

\section{Introduction}

The new era of digitization that we are currently experiencing brings some major changes both in the context of global economy and in the way of organizing and managing classical financial operations as we have known them by now. In the current context of the economy and global finances, we cannot discuss about an integrated economic ensemble without referring to the new blockchain technology that revolutionized the way individuals interact and action in terms of financial trading, investment and online payments. The emergence of a new currency category, the virtual one, required a rigorous regulatory mechanism to control the way transactions are being carried out in a safely manner, thus the blockchain technology incorporates some innovative fundamental principles that made this possible through cryptography, decentralization and public distribution of its content. By eliminating the necessity of involvement of a central authority and its supervision through the regulatory mechanism that is being ensured by the network, cryptocurrencies brought a new and viable way to substitute and complement fiat money with the possibility of storing and trading money exclusively online.

The emergence of a new currency category, the virtual one, required a rigorous regulatory mechanism to control the way transactions are being carried out in a safely manner, thus the underlying technology of crypto - the blockchain technology - incorporates some innovative fundamental principles that made this possible through cryptography, decentralization and public distribution of its content.

Modern cryptography offered many possibilities for further development and implementation of safer ways of storing and sending money online, through asymmetric cryptography and cryptographic hash functions. Throughout this paper we will focus mostly on Bitcoin, which was the first, most capitalized and popular cryptocurrency that was implemented in 2008 by Satoshi Nakamoto, being the starting point for all this enormous crypto environment that we see today. To be more specific, the blockchain is built on a cryptographic hash function called Secure Hash Algorithm with 256-bit output (known under the acronym of SHA-256), which transforms the raw data of a transaction into unique and specific codes called hash values, as to ensure information security and reduced size of stored data. 
Issue no. $27 / 2018$

Bitcoin has brought an extremely important innovation into the digital world of financial transactions, enabling its entire network to control double spending without the need of a central authority to permanently monitor and validate financial data. In addition, the system is fully transparent and all data is available to any user, keeping a ledger with all of the transactions that took place from the beginning of the time, thus reducing the risk of hacking or exploiting the system close to $0 \%$. Also, because the network is being monitored by its own end-users, a new activity has emerged as a consequence of this fact: the cryptocurrency mining. This concept involves the entire process of generating, transmitting and validating network cryptocurrency transactions (Hari Krishnan et al., 2015) and it became a very profitable and exploited activity for some users.

Although the topics of cryptocurrencies and blockchain technology are still dominated by major controversies at a general level, the concept continues to rise and gain popularity especially amongst young people, visionaries or entrepreneurs, expanding its benefits and innovative principles to many business sectors, especially into IT areas, the public sector or research \& development divisions. Besides its financial application, the blockchain has revolutionised the way in which virtual data is stored and handled over a large network, providing new ways of doing business online and remodelling some old classical procedures.

\section{Literature overview}

The global fintech market is growing very fast, and in many directions - not just related to blockchain and cryptocurrencies or the ICOs (Initial Coin Offers), but also related to the artificial intelligence or robot process automation and, in connections with all these, to online payments, financial transfers, lending, openbanking, investments, regtech, insurtech etc.- making it difficult for the researchers to keep pace with this fast development.

However, worldwide we can find plenty of literature and studies concerning the fintech area and Bitcoin in particular, (Chishti \& Barberis, 2016; Reed, 2016; Antonopoulos, 2017; Karame \& Androulaki, 2016; Franco, 2015) that are presenting and analysing the different financial technologies and fintech products, their advantages and benefits for the economy and for the society, as well as their future and perspectives, describing this "marriage" between engineering and economics, rising security and ethical issues and, last 
Issue no. $27 / 2018$

but not least, evaluating their investment and entrepreneurial potential for the visionaries and entrepreneurs, as well as the gains for the early adopters.

Discussing specifically about the Bitcoin, we have to mention, of course, the paper of the anonymous inventor of the Bitcoin, Satohsi Nakamoto (Nakamoto, 2008). This paper, which was entitled: "Bitcoin: A Peer-to-Peer Electronic Cash System" written under this pseudonym - Satoshi Nakamoto, has the rigour of an academic paper, though it was published just on a cryptography mailing list. This "white paper," as it is called now, is introducing and describing the digital currency, named Bitcoin, which is by far the most famous and most used cryptocurrency until today. A few months later, in January 2009, Satoshi Nakamoto released the first version of the bitcoin software, thus the first cryptocurrencies - the bitcoins - were generated. The basic idea of the bitcoin is that online payments can be sent from one party to another without passing by a financial institution, but by using a peer-to-peer network, where the electronic coin is a chain of digital signatures (Nakamoto, 2008. pp.1-2). Practically, the author (or the authors, we don't know, since Nakamoto is a pseudonym) is proposing a system of online payments without the use of a trusted third party, solely relying on a peer-to-peer network using proof-of-work algorithms in order to record all of the online transactions. Almost ten years after its release, the system is perfectly functional with more than $80 \%$ of the total number of bitcoins being already mined - more precisely, 17 million out of 21 million bitcoins that will ever exist, were mined as of April 26 this year (Cheng, 2018) - currently, approximately 200.000 confirmed transactions are made on a daily basis (Blockchain.com, 2018). What is even more fabulous is the explosive development of the cryptocurrency market where we can find today more than 1.890 different cryptocurrencies and tokens (Coinmarketcap, 2018).

Concerning Romania, there are not many books or academic researches related to fintech and blockchain area, and especially about their implications for the economy or the society, though we can find some active Romanian websites that are providing news and analysis through some specific blogs and web platforms, as for example: goanadupabitcoin.ro, bitcoinx.ro, bitcoinromania.ro etc. Yet, in the past five years we have noticed a growing interest amongst the Romanian researchers concerning the bitcoin and the fintech area in general. A first direction of research is about analysing the bitcoin in general, 
as a disruptive innovation, with its particular advantages and disadvantages and its influence in relation with the traditional banking system (Făt \& Pop, 2015; Muresan, Bacali \& Lakatos 2015; Bucovetschi, Badea \& Stanciu, 2018; Rogojanu \& Badea, 2014). A second direction of research is related to the security and risks involved in using or investing in bitcoin or by the potential fraudulent transactions that may happen because of the anonymity specific to bitcoin (Scheau \& Pop, 2018; Petrescu \& Panea, 2018). A third direction of research is related to the viability and the perspectives of the blockchain technology and of the bitcoin, in particular (Dimbean-Creta, 2017; Badea, 2017; Firica, 2017). And finally, a fourth direction of research is related to the opportunity of implementing some regulations for the cryptocurrencies market and to finding solutions for the taxation of the gains made with virtual currencies and other fintech products (Paunescu, 2018).

\section{Research methodology and participants}

This research is intended to offer a fresh perspective on how Romanian students perceive these vast opportunities brought by the digital world, what they really know about this domain, as well as their behaviour regarding online payments and safety usage of their finances online. We have chosen to focus on the current generation of students because they are part of the Generation Z, also named Gen Tech or iGen, which was growing up using the internet and, especially, the mobile internet, on a daily basis and therefore will probably be the larger adopter and beneficiary of these innovative financial technologies. This generation of students, born about twenty years ago, are part of this cohort named Generation $\mathrm{Z}$ and this is why we decided to initiate a study regarding their perception and behaviour concerning the fintech area with the help of a questionnaire applied to randomly selected students of the Faculty of European Studies from Babeș-Bolyai University. For this purpose, we created a questionnaire, consisting on 19 opened and closed questions, designed to get a general insight on the online payment behaviour of the students and their overall knowledge about cryptocurrencies.

The participants at the research were full time bachelor, master or $\mathrm{PhD}$ students from the Faculty of European Studies and we collected 102 valid questionnaires, from 65 female students and 37 male students. When answering the questionnaire each student was asked to 
provide information about their age, gender, field and level of study. All the students were from the Faculty of European Studies, but from different specializations: European Studies, Management, European Administration, European Affairs and Project Management, Diplomacy Studies, etc. Concerning the level of study $88 \%$ were bachelor students, $11 \%$ were master students and $1 \%$ were PhD students.

With this study, our main concern was to identify patterns of behaviour and attitudes towards new financial innovations, enhancing the way in which the Generation $\mathrm{Z}$ is open towards change and novelty on the long term, with concrete evidence and graphics based on the results obtained from the 102 valid questionnaires.

The questions were divided in two groups interconnected. The first half of the questionnaire was focusing on questions related to online shopping/payments, while the second part was mostly focusing on blockchain technology, cryptocurrencies, and especially on bitcoin, as potential instruments for online shopping/payments, but not only. In both categories we inserted questions related to online safety in order to measure students' awareness concerning cybersecurity, in relation with online payments and with cryptocurrencies as well.

Although, as we have showed before, for most of the students, the main subjects of the programmes offered by the faculty do not focus on finance or economy, young Europeanists have a strong inclination towards continuous development and innovation, supporting new ways of action in order to contribute to a better future, a safer and easier way to improve the quality of life in this high-speed lifestyle experienced nowadays. In order to study the implications that the new technologies have on this generation and the future development of the financial domain, throughout this paper we will specifically address and identify the level of knowledge and understanding that the Romanian students have about this domain.

The questions contained by this questionnaire were also applied on subjects from various domains of activity in a previous scientific research (Gligor, 2018) in order to highlight some patterns based on respondents' current field of work/study, with the purpose of determining if the working class is more inclined towards adopting innovation in technology than the youngest generation, strictly depending on their field of activity. In 
Issue no. $27 / 2018$

contrast, this paper is solely focused on finding the level on which the students are aware of these new concepts and how are they using them in their daily life, identifying the necessity for further addressing these issues during classes and future training sessions related to economy \& financial education.

Finally, this research will enable us to draw new conclusions about what could be done in order to raise awareness and promote financial innovations amongst the future professionals for a broader adaptation of the fintech products and services within various areas of activity, with the purpose of finding better ways of addressing forthcoming investments, understanding web security and developing the e-commerce sector towards a sustainable growth of the European economy.

\section{Results and discussions}

As we mentioned already, in the introductory part, the questionnaire presents a series of questions related to the personal data of the respondents such as their current occupation, specific field of study, gender and year of birth. This information will be used to interpret the results, respondents' preferences and their correlation with certain repetitive patterns. Overall, the questionnaire was completed by a total of 102 students (undergraduate or graduate students), some of them being employed or developing their own businesses at the same time. As the numbers suggest, $14,7 \%$ of the students are currently employed and $4,9 \%$ of them are embracing the entrepreneurial challenges in parallel with undertaking a degree program. In terms of gender distribution, we have 65 female respondents and 37 male responders, with a majority of $48 \%$ students born in 1997 . As we have mentioned, due to the fact that most of the students are attending the courses offered by the Faculty of European Studies, the subjects they learn are referring to International Relations and European Studies, specifically on European Administration, Management, European Affairs and Project Management or International Negotiation and Diplomacy.

Starting with the first question, a high percentage of respondents $(94,1 \%)$ declared that they make online shopping or payments. Furthermore, the respondents were asked to jump directly at question 10 in case they offered a negative answer to this question because the next part of the questionnaire is solely focused on finding online payments behaviours 
Issue no. $27 / 2018$

and perceptions. Regarding the frequency of their actions, $47,4 \%$ of the respondents declared that they only make online payments or shopping 3-4 times a year, while another $40 \%$ declared that they do it on a monthly basis. Because the percentages are very similar to one another, the actual frequency of their action cannot be determined on a mainly recurrent pattern overall. Just tiny percent of $9,5 \%$ declared that they make online payments on a weekly basis, as can be seen in figure 4.1 below.

Fig 4.1 - Frequency of Payments

\section{If yes, about how often?}

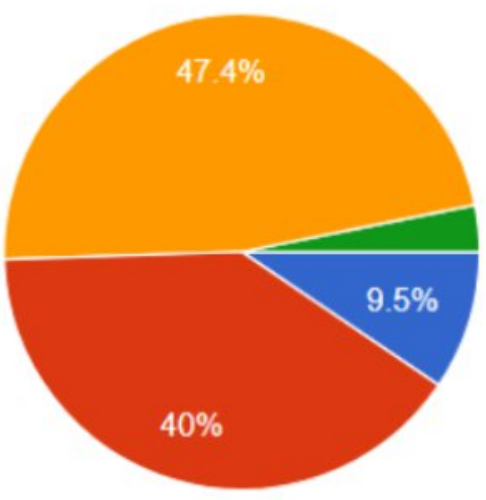

Weekly

Monthly

3-4 times per year

Once a year

In terms of devices used for doing these actions online, as seen in figure 4.2 , the focus is rapidly turning from the classical choices of the past (such as desktop) to the more practical ones (smartphone and tablet). Smartphones and laptops covered the majority of the results with $72,9 \%$ and $68,8 \%$ of answers. We also identified a slightly higher preference for the smartphone technology, which took the e-commerce world to another level in terms of accessibility and user-friendliness. In addition, we could assume that users tend to switch between different types of devices depending on their location, as the majority of respondents proved by selecting multiple answers to this question. 
Issue no. $27 / 2018$

Fig 4.2 - Devices Used

\section{What devices do you use for making online payments?}

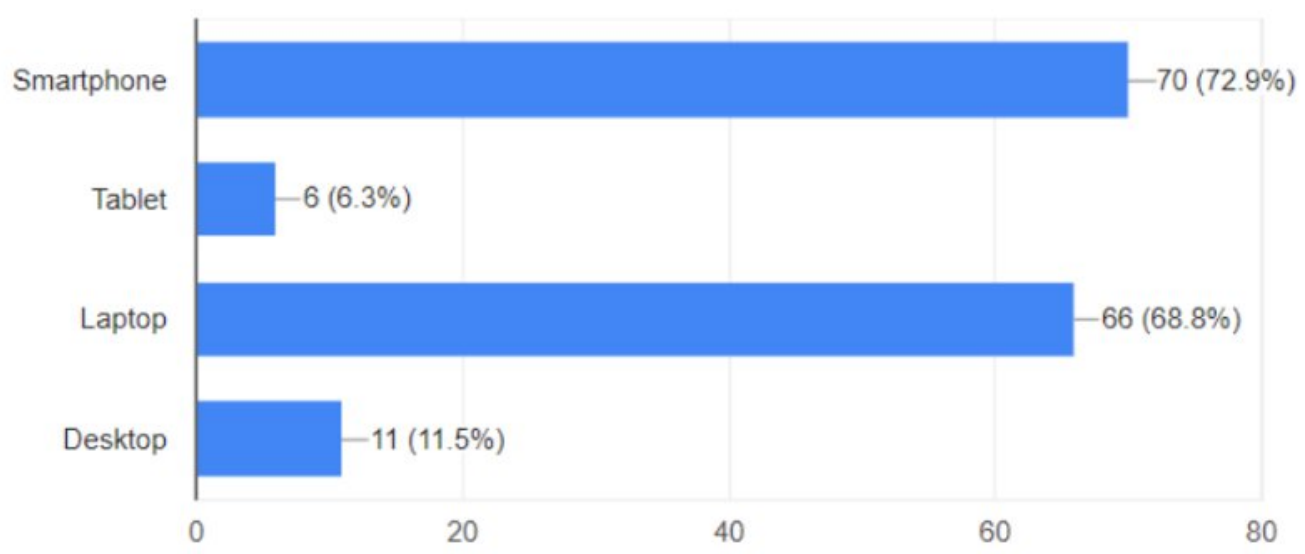

Speaking of the methods of payment that the participants prefer, we observed that there is a strong preference for "cash on delivery" option, but the other methods of payment involving credit or debit card came very close by with similar percentages, as seen in figure 4.3 below. The fact that 48 respondents chose to pay for their goods in person is because they are concerned about their products not being the same as the ones that they have ordered. As a general fact, we observed that participants may sometimes confuse the terms "credit card" and "debit card" or use them interchangeably, due to the fact that in our popular culture and knowledge we define every bank card as a "credit card", (referring to its physical existence, not to the actual service and credit type that it provides). However, if we add together the percentages from debit cards with the credit cards we will see quite clearly that the Generation $\mathrm{Z}$ has no problems in using banking cards for online payments. In contrast, despite the fact that PayPal provides a more secure environment for making online payments, it is not very popular amongst Romanian students anymore, probably due to the fact that it imposes higher fees than other means of transferring money online. 
Issue no. $27 / 2018$

Fig 4.3 - Preferred Payment Method

\section{What type of payment do you use?}

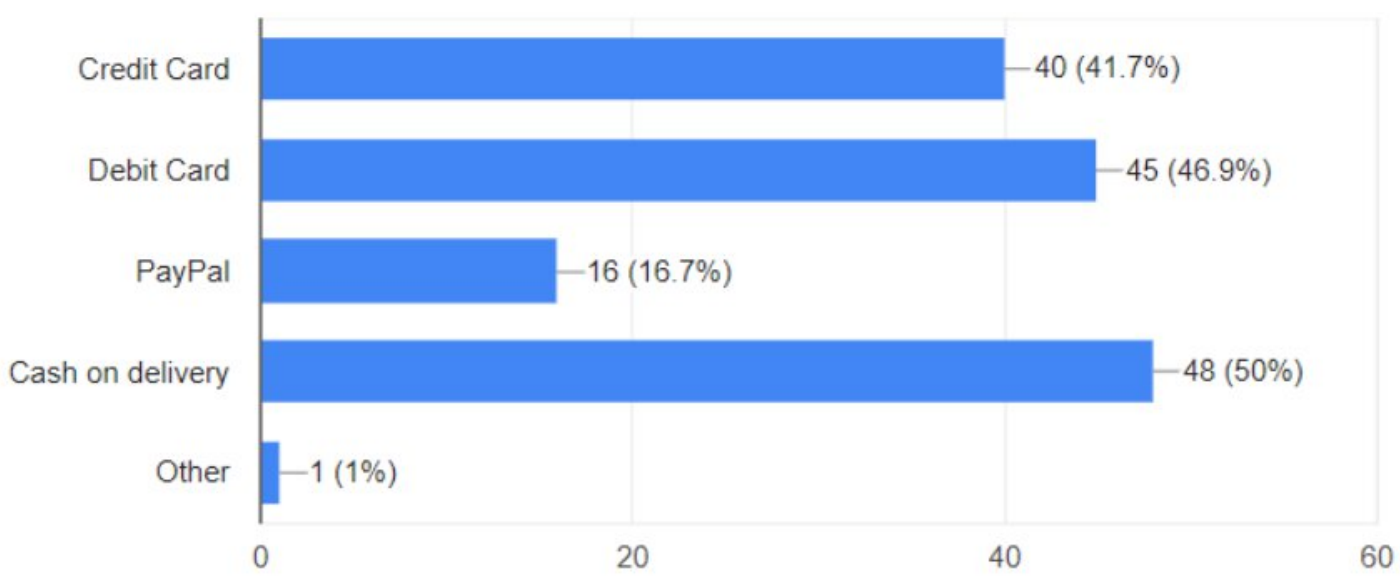

Trying to prove the level of uncertainty that the users have when making online payments on various platforms online and reveal the real motives that determined this attitude, the next question helped us find if their fear of using credit or debit card online is related to the type and structure of the website itself. So, we found out that the majority of respondents, specifically $55,2 \%$ of them prefer to upload their personal and financial data only on popular websites such as Amazon, Alibaba, eBay, Asos or eMag (popular Romanian marketplace) as can be seen in figure 4.4 below. The level of trust provided by these platforms is slightly higher due to the fact that they have a very well-defined structure and use multiple layers of protection against online fraud, using some special payment processors. On contrast to this category, $21,9 \%$ of respondents do not pay attention to the type of website and its security measures when making online payments. Altogether, if we add the 5.2\% of students that are more willing to buy from smaller websites (probably searching for special or niche products), we reach an impressive percent of $82.3 \%$ of students who are willing to use their bank card to make online shopping from popular sites, smaller sites or whatever, showing the fact that they are very comfortable with this form of payment. At the same time, a positive thing is 
Issue no. $27 / 2018$

that they are well-aware of the dangers of the cybercrime, for about the same percent $81.9 \%$ (question no.6: “Are you aware of the dangers of cybercrime?"). This high awareness is in a strong correlation with the fact that only $15,6 \%$ of respondents stated that they had experienced money loss while making online shopping meaning that they took precautionary measures (question no.7: Have you ever experienced a money loss while shopping online?").

Fig 4.4 - Website Structure and Security Measures

\section{On which sites are you more willingly to use your credit/debit card details?}

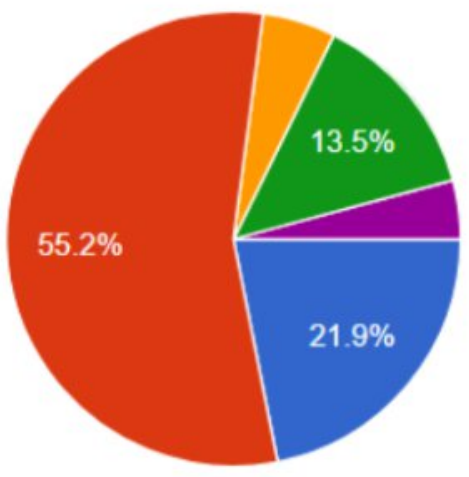

Doesn't matter

Only on popular websites (e.g. Amazon, Alibaba, eBay, Asos, eMag, etc)

On smaller websites

I try to avoid using my credit card details online, if possible

I will never use my credit card details online

When asked what was the reason for losing money online, as we can see from figure 4.5, the main reason indicated was the fact that they payed for a product in advance, without receiving it after that. Overall, this main reason $(57.8 \%)$ has no relation with cybercrime or other hacking techniques available online. Moreover, this answer also explains why so many students chose to pay with "cash on delivery" (see question no.4), not because they didn't trust bank card or PayPal option, but because they had previous experiences of not receiving the product they have paid for. Just 3 respondents declared that they were victims of some sort of online fraud or social hacking tricks, causing them to lose money due to these facts. 
Issue no. $27 / 2018$

Fig 4.5 - Reasons for Losing Money Online

\section{If yes, what was the reason?}

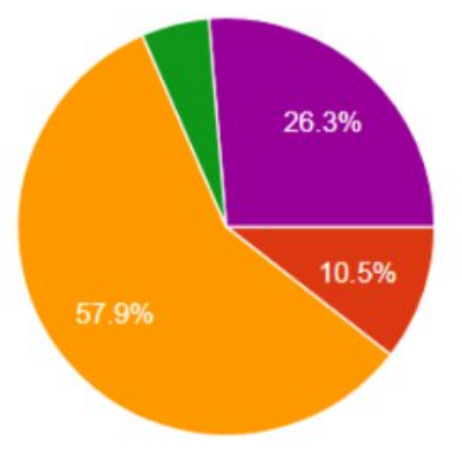

Malware viruses

Online fraud

Paid in advance without receiving the product

Became a victim of a social hacking trick

Other

In order to identify if the respondents know how to protect their assets and financial data while shopping online, the next question addressed this specific issue by asking them what measures do they consider taking in order to protect themselves online. The most common responses were: "giving less personal information or minimising the use of online payment processors", "using only trusted websites based on reviews from other people", "using only safe terminals or websites for making online payments", "be aware if the GDPR is applied correctly", "using antivirus software and browser security extensions", "checking if the website is secured" or "using strong passwords". Though, the majority of respondents $(53 \%)$ did not have any input to this question or declared that they do not take any special measures for protecting themselves online.

The next part of the questionnaire was focused towards identifying the level of knowledge and real hands-on experience with cryptocurrencies that Romanian students have, presenting some yes-or-no questions in relation to this topic. All the percentages gathered at these multiple questions are presented below in figure 4.6. The first question addressed a general knowledge level, trying to identify if the students have heard about the concept of cryptocurrency, without naming a specific type of crypto. As a result, a very high percentage 
Issue no. $27 / 2018$

of the respondents offered a positive answer to this question $(75,5 \%)$. The next question had the purpose to get a little bit more technical, in order to identify if the respondents are familiarised with the underlying concept behind cryptocurrencies: the blockchain. In contrast to the first round of positive answers, at this question only $36,3 \%$ of respondents offered a positive answer. In terms of actually having and/or using Bitcoins, just a small number of $16,7 \%$ of respondents offered a positive answer to this question. This might be related to the fact that mining Bitcoin in 2018 is almost impossible for a regular student and the price to buy it is also prohibitive for them. A high percentage of $83,3 \%$ of respondents declared that they are familiarised with the concept of Bitcoin mining, surpassing the first percentage of $75,5 \%$ that declared they have heard about crypto. Another explanation is that the word "Bitcoin" that appears in the question is far more known that "cryptocurrency". Also, we assume that this result is based on the fact that the coin mining activity has increased with $34,0000 \%$ over the course of the year (Symantec Corp., 2018), after Bitcoin reached the highest value of $\$ 19,783$ in December 2017 (Morris, 2017).

Fig 4.6 - Cryptocurrency Knowledge and Usage

10. Have you ever heard about cryptocurrencies?

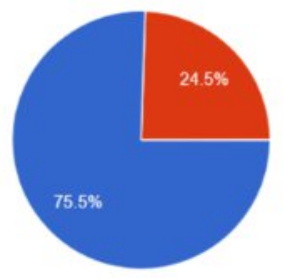

12. Have you ever had or used Bitcoins?

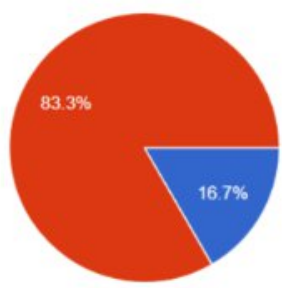

11. Do you know what is blockchain technology?

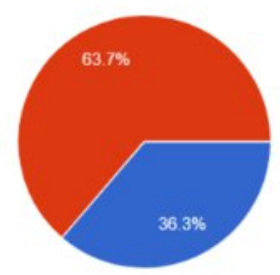

13. Do you know what is Bitcoin mining?

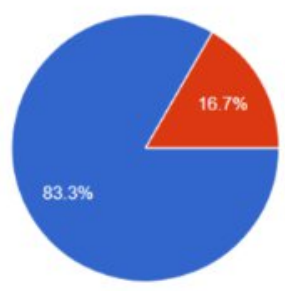


Issue no. $27 / 2018$

The next question was focused on finding out if the respondents know how many Bitcoins exist currently, meaning how many of them have been already mined from the total of 21 million. Only 9 students offered a correct answer to this open question, stating an interval between 16 and 17 million Bitcoins being already on the market. Almost $78 \%$ of respondents did not have any input to this question or stated that are not aware of this fact at the moment. We have deliberately inserted this very technical question in order to see how deep the students' knowledge about Bitcoin goes.

Trying to understand better the level of knowledge and expertise the respondents have about this fintech area, we wanted to identify what exactly do they know or think about the advantages and disadvantages brought by the cryptocurrency market, especially by Bitcoin. Through an open question, we identified that the most common advantages mentioned were: "fast transfer", "comfortable and secure system", "no additional taxes on transfer", "a safer way to transfer money", "transparent information", "better control over money", "no implications from third party entities", "anonymity", "the system is easy to use", "untraceable way of transferring money", "fast processing", "no need for a bank deposit", "no bureaucracy", "decentralisation", "good option for investments", "free market", "system is not controlled by government", "smaller risk of online fraud or cybercrime". Besides these, there were approximately 40 null answers. Even though a quite large percentage of respondents did not offer an answer to this question, the other answers were very accurate, proving that the students were capable of correctly identifying the advantages of using crypto even though they do not have too much practical experience in using these financial technologies.

On the other hand, the same was true when the students were asked about the disadvantages they think cryptocurrencies bring to the end-users, and even more, they indicated almost the same answers. The most common answer was "high volatility" (expressed directly or in other similar words, with approximately 20 mentions), followed by answers like: "not regulated", "risky" or "limited access on the market" with multiple mentions. 44 of the respondents did not offer any input to this question. As expected, respondents identified the disadvantages correctly, mainly focusing on the most popular ones 
Issue no. $27 / 2018$

and on side effects brought by this new type of decentralised system, namely the blockchain technology.

When asked about what other types of crypto do they know, the majority of respondents replied with Ethereum (20 mentions), Ripple (11 mentions), Litecoin (8 mentions) or Monero (3 mentions). There were a few answers containing some crypto or token names which are less popular or used for some specific domains such as: Bitcoin Cash, Dash, OneCoin, HempCoin, Tron, Wanchain, Basic Attention Token, Paccoin, Cardano, Stellar, Neo, Dogecoin, PutinCoin or NameCoin. 2/3 of respondents gave null answers to this question or stated that they do not know any other types of cryptocurrencies besides Bitcoin at the moment.

In order to prospect the future implications that the respondents could have in the cryptocurrency domain, the next question was addressed as to find out if they see this domain as an investment opportunity (question no.18 "Do you think it's worth investing in cryptocurrencies? Would you consider doing it in the future?"). As a result, the majority of respondents $(55,9 \%)$ chose the middle answer "maybe", leaving the door open for future action in this direction if the situation will be favourable. The negative and positive answers percentages came very close to one another, with $20,6 \%$ for the negative side and $23,5 \%$ for the positive one, as can be seen in figure 4.7 below. Overall, almost $80 \%$ of the students did not give a negative answer, having an open-minded perspective towards this opportunity in the future. 
Issue no. $27 / 2018$

Fig 4.7 - Investment in Cryptocurrencies

\section{Do you think it's worth investing in cryptocurrencies? Would you consider doing it in the future?}

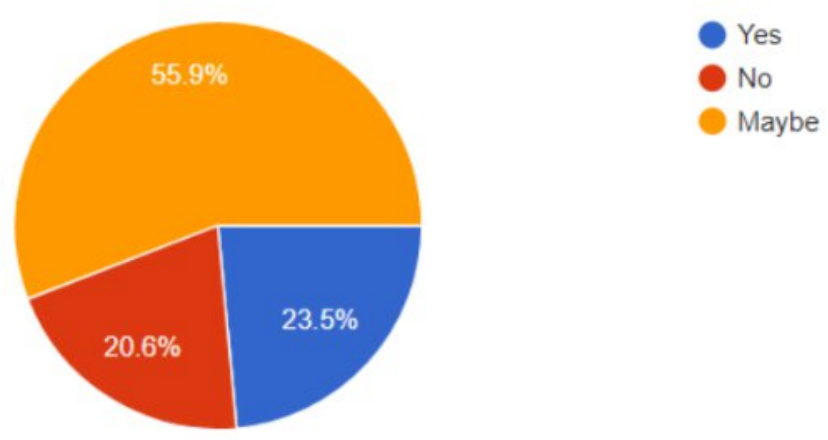

The last question was focused on finding out if the respondents consider that using cryptocurrencies for online payments is safer than other conventional methods. As the results showed, the percentages were very balanced, with 52\% negative answers and $48 \%$ positive answers, proving that the views and thoughts over this subject are very different in general, depending very much of the level of awareness, knowledge and perceptions that the respondents have regarding online security. As a pattern, we observed that the respondents who chose a positive answer to this question where those that identified correctly the advantages and disadvantages of using cryptocurrencies (at questions no. 15 and 16), giving pertinent answers about this domain from their personal experience or general knowledge. In contrast, the students that offered a negative answer to this question had a higher percentage of null answers at questions no. 15 and 16, suggesting the fact they do not know what exactly this domain represents and how is it different as a concept, thus they could not evaluate its secure infrastructure objectively. 
Issue no. $27 / 2018$

\section{Conclusions}

In this paper we indented to analyse the perception and behaviour of Romanian students from Generation $\mathrm{Z}$ concerning the fintech area and especially the online payments and cryptocurrencies. The data we collected from our questionnaires clearly indicated that almost everybody from this generation, which grew up in the internet era, was doing online shopping or online payments, with half of them doing this on a monthly basis. We also found out that they are very comfortable in using debit or credit cards for online payments, while at the same time being aware of the dangers brought by the cybercrime associated with these types of payments in the online environment. Regarding the cryptocurrencies, the answers were a little more mixed. However, we can identify two main patterns that divided the students into at least two categories. In the first category are the students that know what is the blockchain technology and the mining process, they can name other cryptocurrencies besides the bitcoin, they can identify accurately the main advantages and disadvantages of bitcoin and, they consider that using cryptocurrencies for online payments is safer than using conventional methods. In the second category, we can find the students who may know about the bitcoin mining, but not about the blockchain technology, who cannot name other cryptocurrencies except bitcoin or have difficulties in presenting the advantages or disadvantages of the bitcoin but, nevertheless, they are curious and leave the door open when asked about the possibility of investing and using the bitcoin in the future.

Therefore, generally speaking, we can say that generation $\mathrm{Z}$ is very inclined towards innovation and continuous technological development, being ready to embrace the challenges that the future could bring along with these changes. Even though the students are still at a younger age and generally not employed yet, they managed to see the benefits and advantages these technologies could bring on the long term as an investment opportunity, but mostly the fact that these represent a very practical way of making online payments in a secured manner, fast and almost costs free. Generation $\mathrm{Z}$ likes the freedom, the mobility, the coolness and the lightness brought by the fintech products. This is valid all over the world, including the emerging markets. It should not be a surprise that in China for example, the cash, as we know it traditionally, is not the "king" anymore and the fintech industry has an explosive development and, as a result, Ant Financials - a so called "unicorn", the Chinese 
Issue no. $27 / 2018$

fintech company that includes Alipay - has a capitalization of 150 billion dollars, which is by far larger than Goldman Sacks or American Express, that both have a long tradition and huge notoriety in banking (Miller\& Chen, 2018).

Despite the fact that the technology that sits behind this whole concept is very complicated for a non-technical person (and for that reason the whole concept may sound strange or unstable), the financial aspect should not be overlooked, because it basically refers to the same general concepts applied in every other aspect related to economy and finances. The underlying principles of demand and supply, capitalization or market analysis are still the same as they have always been.

\section{References:}

- ANTONOPOUlOS, Andreas M. (2017), Mastering Bitcoin, USA, O’Reilly Media Inc

- BADEA, L. (2017), Virtual Currency - A Viable Alternative To The Classical Currency, Proceedings of the International Conference: Information Society and Sustainable Development, IVth Edition, April 28-29

- BUCOVETSCHI,O, BADEA D., STANCIU R. (2018), Blockchain technology - a new approach in business environment, Annual Session of Scientific Papers IMT ORADEA 2018

- CHENG, E. (2018), There are now 17 million bitcoins in existence - only 4 million left to 'mine', CNBC, April 26, 2018, available online at: https://www.cnbc.com/2018/04/26/there-are-now-17-million-bitcoins-in-existence--only4-million-left-to-mine.html (accessed August 30, 2018)

- CHISHTI S, BARBERIS J. (2016), The FINTECH Book: The Financial Technology Handbook for Investors, Entrepreneurs and Visionaries, John Wiley \& Sons

- DIMBEAN-CRETA, O. (2018), Fintech - already new fashion in finance, but what about the future?, Quality-Access to Success, Vol. 18, S3, October 2017

- DELLOITE Report (2016), FinTech in the CEE region. Charting the course for innovation in financial services technology, available at:

- https://www2.deloitte.com/content/dam/Deloitte/global/Documents/AboutDeloitte/central-europe/ce-fintech-in-cee-region-2016.pdf (accessed August 20, 2018) 
Issue no. $27 / 2018$

- FĂT, C., POP, F. (2015), Criptomonedele o realitate a zilelor noastre, International Conference SUSTAINABLE DEVELOPMENT IN CONDITIONS OF ECONOMIC INSTABILITY; $4^{\text {th }}$ edition; June 26-27 2015, available online at: http://conferinta.academiacomerciala.ro/CD2015/ARTICOLE/2/CRIPTOMONEDELE\% 200\%20REALITATE\%20A\%20ZILELOR\%20NOASTREatPop.pdf (accessed July 20, 2018)

- FIRICA, O. (2017), Blockchain Technology: Promises and Realities of The Year 2017, Quality-Access to Success, Vol. 18, S3, October 2017

- GLIGOR, R. (2018) - "Bitcoin \& Blockchain Technology Explained. Data Security Concerns and Issues ", Bachelor Thesis.

- KARAME, G., ANDROULAKI, E. (2016), Bitcoin and Blockchain Security, Artech House.

- KESZTHElyI, A. (2013), About passwords, Acta Polytechnica Hungarica, vol.10, no. 6; pp. $99-118$

- KRISHNAN H. et al., Cryptocurrency Mining - Transition to Cloud, (IJACSA) International Journal of Advanced Computer Science and Applications, Vol. 6, Nr. 9, 2015, pp. 115-125

- FRANCO P. (2015), Understanding Bitcoin - Cryptography, Engineering and Economics, Ed. John Wiley and Sons Ltd

- Lazányi K. (2014) - Entrepreneurs of the future; Serbian Journal of Management 9 (2), pp. $149-158$

- Miller L., CHEN L.Y. (2018), Ant Is Worth 50\% More Than Goldman With $\$ 150$ Billion Valuation, Bloomberg Technology, https://www.bloomberg.com/news/articles/2018-04-11/ant-is-worth-50-more-thangoldman-with-150-billion-valuation (accessed August 31, 2018)

- MURESAN C.M., BACALI L., LAKATOS E.S (2015), General Issues Of Bitcoin Virtual Currency, Revista de Management şi Inginerie Economică, Vol. 14, Nr. 4; pp. $818-824$ 
Issue no. $27 / 2018$

- MORRIS Z. David, (2017), "Bitcoin Hits a New Record High, But Stops Short of \$20,000”, Fortune.com, available at http://fortune.com/2017/12/17/bitcoin-record-highshort-of-20000/. (accessed August 20, 2018)

- NAKAMOTO, S. (2008), Bitcoin: A Peer-to-Peer Electronic Cash System, available at: https://bitcoin.org/bitcoin.pdf (accessed August 20 2018)

- NISTOR I, PAUN D. (2009), Perspectives on the Financial Intermediation in Romania Within Changing Market Conditions, 10th International Conference, Finance and Economic Stability in the Context of Financial Crisis, DECEMBER 11-12, 2009 Theoretical and applied economics supplement, pp. 309-314

- PAUNESCU, M., (2018), Exploratory study on accounting and taxation of virtual currencies by Romanian companies, Audit Financiar, vol. XVI, no. 2(150)/2018, pp. 239248

- PETRESCU A., PANEA O. (2018), Natural flow: E-commerce, Cyber-, Bitcoin, Blockchain, Proceedings of the Romanian Academy, Series A, Special Issue/2018, pp. 303-308

- RACOLTA-PAINA, N. D., ANDRIEȘ, A. M. (2017), Identifying Entrepreneurship Readiness for the Application for the Lean Startup Practices in the Service Industry Case Study: Romania, ECOFORUM, Vol 6/No.3, pp. 200-210,

- REED J. (2016), Blockchain: Blockchain, Smart Contracts, Investing in Ethereum, Fintech, CreateSpace Independent Publishing Platform

- ROGOJANU A., BADEA L. (2014), The issue of competing currencies. Case study Bitcoin, Theoretical and Applied Economics Volume XXI (2014), No. 1(590), pp. 103 114

- SCHEAU, M.; POP, S. (2018), Cybercrime evolution, International conference KNOWLEDGE-BASED ORGANIZATION, Volume 24, Issue 1, P 225-229

- Symantec Corporation (2018), Internet Security Threat Report, volume 23, 04/18. 
Issue no. $27 / 2018$

Web resources:

1. Blockchain.com (2018) - The number of daily confirmed Bitcoin transactions, https://www.blockchain.com/charts/n-transactions\#

2. https://bitcoinx.ro/

3. http://bitcoinromania.ro

4. https://coinmarketcap.com/all/views/all/

5. https://goanadupabitcoin.ro/bitcoin-romania

6. The Pulse of Fintech (2018) -

https://assets.kpmg.com/content/dam/kpmg/xx/pdf/2018/07/h1-2018-pulse-of-fintech.pdf 